\title{
Favor Trading in Public Good Provision
}

\author{
Sarah Jacobson ${ }^{1}$ \\ Department of Economics \\ Williams College \\ 24 Hopkins Hall Dr. \\ Williamstown, MA 01267 \\ Sarah.A.Jacobson@williams.edu \\ Phone: 413-597-2476
}

Fax: 413-597-4045

\author{
Ragan Petrie \\ Interdisciplinary Center for Economic \\ Science (ICES) \\ George Mason University \\ 4400 University Drive, MSN 1B2 \\ Fairfax, VA 22030 \\ rpetrie1@gmu.edu
}

April 2013

Abstract

Favor trading is common. We do something nice for someone, and they do something nice in return. Several motives might underlie such behavior, including altruism, strategic motives, and direct or indirect positive reciprocity. It is not yet well-understood how these fit together to affect behavior, how they interact in various institutional structures, and how they play out over time. We use a laboratory experiment to study the elements and dynamics of favor trading in a particular setting: the private provision of a public good. In our experiment, giving subjects the ability to practice targeted reciprocity by making a simple, low-cost change in information provision increases contributions to the public good by $14 \%$. Subjects reward group members who have previously been generous to them and withhold rewards from ungenerous group members. Strategic concerns cannot explain all of this behavior, and it must be at least partly due to direct reciprocity. When someone cannot directly benefit from favor trading, he gives much less to the public good. People thus excluded from the "circle of reciprocity" provide a clean and strict test of indirect reciprocity. Contrary to previous studies in the literature, we do not observe indirect reciprocity.

Keywords: public goods, direct and indirect reciprocity, experiment, peer-to-peer fundraising JEL Classifications: C92, H41, D01

\footnotetext{
${ }^{1}$ Corresponding author. James Cox, Vjollca Sadiraj, and participants in various workshops, conferences, and seminars (notably at Georgia State University) provided helpful comments. We thank the National Science Foundation (Award SES-0752754) and Georgia State University for funding this research.
} 
"Do: Get excited. Engage your network, rally the masses and have fun doing it." - charity:water advice on peer fundraising

"If you don't give back no one will like you." - Crowdrise tagline

\section{Introduction}

Favor trading is ubiquitous. We lend tools to a neighbor and later ask him to watch our house while we are away. We recommend a friend for a job and then entreat him to give to our favorite charity or cause. Sometimes the exchange is less direct. We may support the school band of a colleague's child with no obvious opportunity for personal benefit in the near future. Such exchanges between non-kin people are common and have been attributed to motives such as strategic self-interest, reciprocal altruism, and indirect reciprocity. While any of these may be plausible explanations for reciprocal exchanges, we know little about which factors drive behavior and how they interact to increase or reduce cooperative behavior. This is important to understand because each motive has different implications for the success of reciprocal environments. In institutions where cooperation is pro-social, the ability to return favors and the information that enables such an action may be important determinants of the efficiency of outcomes. ${ }^{1}$

In this paper, we study the motives behind favor trading and attempt to unpack them to better understand which are most salient. While favor trading occurs in many environments, we study the private provision of a public good because favor trading in this setting may serve a special pro-social role. We use linear public goods experiments to explore this because they cleanly simulate an environment in which cooperation increases efficiency. We systematically

\footnotetext{
${ }^{1}$ Social favor trading may drive behavior in many cooperative settings. The same dynamic may exist when time and effort are solicited, such as in a volunteer advisory board. Klein (1990) argues that peer pressure played a role in the funding of turnpikes in early America. Jackson et al. (2012) show that favor trading can informally enforce contracts (including credit exchanges) within a social network using data from Indian villages, and La Ferrara (2003) discusses the role of intergenerational favor-trading in a similar context of informal credit in Ghana.
} 
manipulate the characteristics of the institution to study the importance of strategy, direct reciprocity, and indirect reciprocity.

Our study can also be understood in the context of grassroots fundraising for charities. Charities frequently encourage supporters to tap into their social networks to increase donations. A supporter can trade favors with friends by asking them to contribute to his favorite cause with the expectation of being asked to support their causes in the future. Social media has made this process easier than ever with online tools like Facebook Causes and DonorPages. ${ }^{2}$ Brick-andmortar institutions like the Girl Scouts of the USA, the Susan G. Komen Race for the Cure, and the Walk to Cure Diabetes use a combination of online solicitation and personal contact to fundraise through networks. ${ }^{3}$

The popularity of this social fundraising suggests that the method is fruitful. Favor trading in this environment is possible because of heterogeneous preferences for public goods and because the institution makes contribution information public. Our results, seen in this context, are important to both practitioners and researchers. We identify the role of reciprocity separately from the role of strategy as both work to boost contributions. Our results suggest that tapping into social networks could be a low-cost and effective way to raise contributions to a public good.

To illustrate how favor trading in support of a public good may function, we present an example. Suppose Joe and Frank are coworkers. Joe's son is in Boy Scouts and Frank's daughter is in Girl Scouts. Each organization has an annual fundraiser: Joe's Boy Scout sells popcorn in

\footnotetext{
${ }^{2}$ About one third of young people use email and social networking sites to inform friends of a charity (Preston, 2010).

${ }^{3}$ Girl Scout troops send girls out into their communities every year to sell cookies in a $\$ 700$ million business to raise money for their Scouting activities (Girl Scouts of the USA, 2011)
} 
January and Frank's Girl Scout sells cookies in February. For each fundraiser, the children and their families solicit contributions from their social networks. Also, purchase (donation) decisions are fairly public. Each man has an interest in his own child's fundraiser because of the family's stake in the organization's success. As a result, Joe will buy popcorn and Frank will buy cookies. Also, Joe wants Frank to buy popcorn and Frank wants Joe to buy cookies. Even if Frank does not care about Boy Scouts (or popcorn), he may buy Joe's popcorn in the hope that Joe will reciprocate when Frank's cookie fundraiser comes around next month. These peers use the promise of future reciprocation to pressure each other to give to charity.

This reciprocal giving may work in many ways. ${ }^{4}$ It may be strategic, in which case a person gives only to garner a reward later and giving declines when future rewards are no longer possible. This motive was studied and compared to other-regarding preferences in Cabral et al. (2012), who find evidence of cooperation driven by strategic concerns but also find evidence of other-regarding preferences. Dreber et al. (2011) also study strategic cooperation as compared to cooperation based on social preferences, concluding that both are important, and Reuben and Suetens (2012a) find that much of the cooperation in their repeated Prisoner's Dilemma game is strategic. Reciprocal giving may be driven by direct reciprocity (i.e. reciprocal altruism), models of which include Rabin (1993) and Cox et al. (2008), in which case the giver's preferences are increasing in the payoff of a past benefactor. ${ }^{5}$ Indirect reciprocity may play a role if an actor

\footnotetext{
${ }^{4}$ As Sobel (2005) discusses, there are many terms to describe reciprocity. We will use phrases like "reciprocal act" to describe all kind acts that seem to respond to a kind act received in the past. We will describe these acts as "strategic" (or "instrumental," per Sobel) if they are self-serving. We will use the phrases "direct reciprocity" and "indirect reciprocity" to describe only acts that are rooted in other-regarding preferences ("intrinsic," per Sobel).

${ }^{5}$ Direct reciprocity or gift exchange has been studied extensively in a variety of settings (e.g. Fehr et al. 1993; Berg et al. 1995; Charness and Rabin 2002; Cox 2004; List 2006; Gneezy and List 2006).
} 
rewards a good deed done to a third party (e.g. Nowak and Sigmund 2005; Seinen and Schram 2006, Engelmann and Fischbacher 2009). ${ }^{6}$

While there is ample evidence that people contribute to public goods, it is also clear that cooperation is difficult to sustain (Ledyard, 1995; Chaudhuri, 2011). Reciprocal-type forces based on subjects' reputations may sustain pro-social cooperative behavior (e.g. Trivers, 1971; Fischbacher, Gächter, and Fehr 2001; Milinski et al. 2002; Gächter 2007), including through punishment and reward (e.g. Fehr and Gächter 2000; Andreoni et al. 2003; Masclet et al. 2003; Bochet et al. 2006; Houser et al. 2008; Almenberg et al. 2011). There is growing evidence that social forces also drive giving outside the lab; for example, DellaVigna et al. (2012) find evidence of "social pressure" in door-to-door fundraising.

Our experimental design adds to this literature by identifying which institutional elements are important for reciprocity to boost giving to a public good. ${ }^{7}$ We are also able to determine the relative importance of direct reciprocity rooted in other regarding preferences, indirect reciprocity, and strategic self-interest. ${ }^{8}$

We induce heterogeneous interests in "causes" by assigning asymmetric returns to the public good. In every round, one person (the "Stakeholder") gains more from the public good than do the others in the group (just as Frank cares about and thus has a stake in the Girl Scouts'

\footnotetext{
${ }^{6}$ Of the many types of indirect reciprocity that have been studied, the most relevant to our setting include the "downstream reciprocity" of Nowak and Sigmund (2005), the "third party reward" of Almenberg et al. (2011), and the "social indirect reciprocity" of Stanca (2009).

${ }^{7}$ Non-experimental studies of peer solicitation could suffer from endogeneity. For example, Long (1976) found that the more "personal" a donor solicitation, the more contributions were solicited. This was because a more personal solicitation allowed the fundraiser to exert peer pressure on the donor. However, the analysis will likely overestimate this relationship. Personal solicitations are more costly to perform, so charities may limit their most personal solicitations to donors known to be generous. However, Meer and Rosen (2011) find a similar result more strongly identified based on a solicitee's place in an alphabetized list.

${ }^{8}$ We do not examine network formation and solicitation, but instead focus on the roles of social preferences and information in determining contribution behavior in a group.
} 
success). A group with a Stakeholder is similar to Olson's (1965) “privileged group,” as studied in Reuben and Riedl (2009). ${ }^{9}$ We make the privileged group even more effective by making the Stakeholder position rotate through group members, creating opportunities for targeted reciprocal acts. The game is repeated and every person in the group has a turn at being the Stakeholder. To examine the importance of reciprocity, we compare behavior when subjects have full information regarding each other's actions (and thus can condition their giving on others' past acts) and when they do not have that information.

In a final treatment, we examine whether a group member who never has a "cause" will indirectly reciprocate by using his contribution to reward people who have been kind to others. This differs from many studies (e.g. Engelmann and Fischbacher, 2009; Seinen and Schram, 2006) that have found support for indirect reciprocity in that the people whose actions we study gain very little from a group norm of cooperation. In previous studies, subjects who indirectly reciprocate gain a large benefit if the group establishes a general norm of cooperation. Our treatment provides a stricter test.

We find that the effects of allowing people to engage in targeted reciprocity are positive and significant. Average contributions increase by $14.4 \%$. While some reciprocal acts may be strategic, we show that not all are. Some are more consistent with direct reciprocity. We do not find evidence of indirect reciprocity. When a person's benefit from a norm of cooperation is indirect, he does not reward kindness with kindness. Taken together, these results suggest fundraising within a social network can have a significant impact on increasing donations, but only if there is an opportunity for favors to be returned.

\footnotetext{
${ }^{9}$ Isaac and Norton (forthcoming) study a similar role, which they call an "agent of grace," and find that the presence of such a person may slightly boost group members' contributions.
} 
The paper proceeds as follows. The next section explains the general experimental design. Section 3 describes three experimental treatments. In Section 4, we present results. We conclude in Section 5.

\section{Experimental Design}

The experiment is a linear public goods game with publicly revealed contributions and asymmetric payoffs. The design mimics a peer-to-peer fundraising network that allows favor trading. In each treatment, subjects are assigned into five-person groups. Each person $i$ has an endowment of $z$ tokens in each round $t$. He must choose how many tokens $g_{i t}$ to allocate to a public investment with some return to all group members and a private investment with return $a$ to himself. In each round, one group member (with index Stake $e_{t}$ ) is the Stakeholder: he has a bigger stake in the public good because he gets a higher return $c$ from tokens invested there as compared to the non-Stakeholder return $b$. The parameters are such that $b<a<c$ : nonStakeholders maximize profit by not contributing and Stakeholders maximize profit by contributing. The Stakeholder position rotates through group members. Payoffs are:

$$
\pi_{i t}=\left\{\begin{array}{ll}
c \sum_{j} g_{j t}+a\left(z-g_{i t}\right) & \text { if } \text { Stake }_{t}=i \\
b \sum_{j} g_{j t}+a\left(z-g_{i t}\right) & \text { if } \text { Stake }_{t} \neq i
\end{array}\right\}
$$

Parameters also ensure that $a<4 b+c$, so that the social optimum is achieved if everyone contributes fully. Since $c>a$, even a selfish Stakeholder always contributes to the public good. Since $b<a$, non-Stakeholders face a dilemma: they maximize profit by keeping all of their tokens, but this free riding is anti-social. The Nash equilibrium if all actors are selfish and have common knowledge of others' selfish preferences is that Stakeholders should 
contribute fully and non-Stakeholders should contribute nothing. Non-Stakeholder contributions are costly cooperation: they will be the focus of our analysis.

A selfish person would be predicted to free ride when he is non-Stakeholder. An altruist or a person with warm glow preferences would contribute a positive amount if his marginal gain in utility from increasing others' payoffs is larger than his marginal utility loss from the reduction in his own payoff. Against this backdrop, the strategic and reciprocal forces described above will be at play, given sufficient information.

If a subject can only see a list or summary of his group members' contributions, he may exhibit conditional cooperation. However, the asymmetry provided by the Stakeholder position and a more complete information set (information on when each group member will be Stakeholder and a contribution history for each member) allow targeted reciprocal actions to occur. Others' past behavior can help a subject decide when to make or withhold nonStakeholder contributions. A subject $i$ may interpret the contribution of another subject $j$ when $i$ is Stakeholder as a signal of $j$ 's kindness since $j$ 's contribution increased $i$ 's earnings. Subject $i$ may reciprocate by contributing when $j$ is Stakeholder. If another subject $k$ is less generous during $i$ 's Stakeholder stint, $i$ may withhold contributions when $k$ is Stakeholder.

These reciprocal acts can be of two varieties. On the one hand, they may be motivated by other-regarding preferences - that is, they may reflect direct reciprocity. In this case, a person's willingness to pay to increase another person's payoff may depend on the history he has observed. On the other hand, if a subject is strategic, observed history may change his beliefs about the best strategic action. If subject $j$ seems to be potentially generous and $i$ is strategic, subject $i$ may think that if he contributes when $j$ is Stakeholder he will gain favor and earn future 
benefits when the contribution is reciprocated. The benefits of this strategic behavior are greatly reduced after a subject passes his last stint as Stakeholder, so even in the full-information Stakeholder setting, strategic motivations drop discontinuously in final periods. Thus, reciprocal giving in late rounds may distinguish other-regarding preferences from strategic giving. ${ }^{10}$ In addition, a subject may exhibit indirect reciprocity: the drive, based in other-regarding preferences, to reward another subject who has previously been kind to other subjects rather than to himself.

In any of these ways, information about contributions made by each group member and the timing of when each group member will be Stakeholder allows subjects to give reciprocally. ${ }^{11}$ If the information on Stakeholder timing and individual contribution histories is suppressed, targeted reciprocal acts (strategic or rooted in other-regarding preferences) are not possible. Thus, we can compare non-Stakeholder contributions across treatments to quantify the effects of allowing targeted reciprocity. Targeted reciprocity may increase total public good provision as subjects use contributions to reward each other. However, even if targeted reciprocal acts occur, it is not a foregone conclusion that provision will increase. For example, if initial contributions are low, reciprocators may respond by reducing contributions so that provision declines.

\section{Experimental Treatments}

We use three treatments: Private, Public, and Ineligible, described in detail below. All use endowment $z=20$ tokens, private good return $a=\$ 0.02$, non-Stakeholder public good return $b=$

\footnotetext{
${ }^{10}$ A misplaced application of a strategic reciprocal rule of thumb, i.e. cooperation caused by the mistaken belief that future rewards can be garnered, could also cause late-round reciprocation. Our study is not designed to examine this possibility. This idea is explored in Reuben and Suetens (2012b), who look at conditional cooperation that happens before end-period defection. This can be contrasted with the end-period cooperation we study.

${ }^{11}$ History could also affect current behavior through contagion: a person treated well (badly) in the past could react by behaving well (badly) solely because they have "caught" a good (bad) mood from their experience.
} 
$\$ 0.01$, and Stakeholder public good return $c=\$ 0.03$. For non-Stakeholders, the personal return from public good contribution is half the private good return; for Stakeholders it is 1.5 times that return. We use a within subject design. Subjects made decisions in all three treatments, in a different group for each treatment, with treatment order varied across sessions. ${ }^{12}$

The experiment is computerized and proceeds as follows. Subjects enter the lab and are given general instructions. ${ }^{13}$ They are told that they will make decisions in three sets of multiple rounds, each with a different group, but they do not know the exact nature of the decisions they will make in each set (treatment) until the treatment-specific instructions are read. The first treatment begins with instructions that explain the information condition and the number of rounds for that treatment. The subjects play through all of the rounds for the treatment. When the first treatment is over, the groups are randomly re-matched. The second and third treatments proceed similarly, each with treatment-specific instructions read first. After all three treatments, subjects complete a questionnaire and are paid anonymously. Subjects' total earnings are the sum of their earnings in each treatment, which in turn are the sum of earnings in each round.

In the software for each treatment, subjects see a decision screen and then, after making a decision, a review screen for each round. In both the decision and review screens, the central feature is the contribution table. This table contains a row for each round in the treatment. Columns contain information on the subject's contribution and the contributions of others in his group, the group's total contributions, and the subject's own earnings. Information is filled into this table after the decision stage of each round and remains visible for the rest of the treatment.

\footnotetext{
${ }^{12}$ We initially chose a within-subject design in order to investigate how an individual's behavior changed across treatments and to organize the data into subject "types." Such analysis did not yield interesting results and are not presented in the paper.

${ }^{13}$ All instructions are available on the corresponding author's website.
} 
The Public treatment, which lasts ten rounds, follows the basic favor-trading public goods design outlined in the previous section. The Stakeholder position rotates through all five group members so everyone is Stakeholder twice. Contributions are publicly revealed and tracked individually, and Stakeholder assignments are common knowledge. Figure 1 shows the Public treatment decision screen (with simulated data). Each group member is randomly assigned a letter code and keeps the same letter code for all ten rounds. The contribution table shows in which rounds each subject will be the Stakeholder. The information contained in the contribution table allows subjects to reward each other for past generosity. For example, if subject $i$ is A and $j$ is $\mathrm{B}, i$ can see how much $j$ contributed in Round 1 when $i$ was the Stakeholder. Subject $i$ can reward $j$ with a large contribution when $j$ is Stakeholder in Round 2, or $i$ may withhold that reward if he deems $j$ 's contribution stingy.

The Private treatment also lasts for ten rounds. As in the Public treatment, the Stakeholder position rotates through all group members so everyone is Stakeholder twice. However, the information environment differs from the Public treatment. Each subject still sees the disaggregated, individual contributions of his group members, but subjects are not assigned letter codes. It is no longer possible to track reputations. Figure 2 shows the review screen for the Private treatment. In each round's row, the contribution table reports the contributions of all group members in a randomly-ordered list, re-shuffled for each round. Further, even if a subject thinks he can identify a group member as being worthy (or unworthy) of reward, he still does not know when that person will be Stakeholder. He only knows when he himself will be the Stakeholder, so he cannot target reciprocal acts toward any other subject.

Finally, the Ineligible treatment is similar to the Public treatment, with public reputations and public Stakeholder timing. However, one member ("the Bachelor") of each five-member 
group is ineligible to be the Stakeholder. The Bachelor is analogous to a member of a social network who has no pet cause for which to fundraise. Because only four subjects are eligible to be Stakeholder, the Ineligible treatment lasts eight rounds so that each eligible subject is still Stakeholder twice. The Bachelor is randomly chosen and remains the Bachelor for the entire treatment. In the screens for the Ineligible treatment (see Figure 3 for the review screen), the Bachelor is indicated in the screen header and in the contribution table as the "Ineligible" person. The Stakeholder position rotation skips the Bachelor: if person D is the Bachelor, the Stakeholder is A, then B, then C, then E, etc.

The main difference between the Public and Private treatments is that direct reciprocity, indirect reciprocity, and strategic reciprocity cannot motivate giving in the Private treatment. Subjects do not have the information they would need to respond to each other's actions. Unconditional altruism and general conditional cooperation, however, can affect giving in both treatments. Any difference between the Public and Private treatments must be due to some combination of targeted direct reciprocity, indirect reciprocity, and strategic giving. (Indirect reciprocity can only be cleanly isolated in the behavior of Bachelors in the Ineligible treatment, but it can still drive behavior of potential Stakeholders in the Public and Ineligible treatments.)

Within the Public treatment, we will be able to see whether subjects are responsive to past generosity. That is, we can see whether they give larger contributions when the current Stakeholder is someone who was previously generous. ${ }^{14}$ This is precisely the favor trading we would expect to see in peer-to-peer fundraising or other non-lab settings. We can identify direct

\footnotetext{
${ }^{14}$ In each round, subjects may respond to the past behavior of both the current Stakeholder and the current nonStakeholders. However, if we detect this kind of responsiveness with regard to only the current Stakeholder's past actions, this is sufficient to demonstrate reciprocal giving.
} 
reciprocity as responsiveness of this type that does not disappear after the subject's last

Stakeholder stint, since at that point strategic considerations have been eliminated.

The Ineligible treatment allows us to investigate indirect reciprocity. The Bachelor herself is not subject to direct reciprocity or strategic self-interest. If the Bachelor gives in a way that responds to the Stakeholder's past generosity, this would be evidence of indirect reciprocity. Also, the presence of a Bachelor shrinks the "circle of reciprocity" from five people to four people. We can study whether this change in the group dynamic affects non-Bachelor contributions. For example, others may be discouraged if Bachelor contributions are low.

The experiments were run in the Experimental Economics Center (ExCEN) at Georgia State University in six separate 20 -subject sessions, for a total of 120 subjects. The software was written in z-Tree (Fischbacher, 2007), and the protocol was double anonymous. ${ }^{15}$ Of the 120 subjects, $75(62.5 \%)$ were female, and the average age was 21.8. The experiment lasted about 90 minutes, and average earnings were \$24.33 (standard deviation \$2.67).

\section{Results}

In our within subject design, each subject participated in all three treatments. The three treatments were run in all six possible orders, with each order run once. We do not observe effects of treatment order on variables of interest so we pool the data across sessions. ${ }^{16,17}$

\footnotetext{
${ }^{15}$ Subjects could not identify which subjects they were interacting with, and the experimenters could not identify which subject made any set of decisions.

${ }^{16}$ There is an order effect in that non-Stakeholder contributions are higher in the Private treatment if the Private treatment is before the Public treatment than if it is not first (43.44 as compared to 27.81 percent of endowment, Mann-Whitney test $p=0.002$ ). Because of this, if Private is first, there is no statistical difference between Private and Public non-Stakeholder contributions (paired Wilcoxon signed rank test $p=0.368$ ). The Private treatment may be more difficult to understand when presented first. This is supported by the fact that Stakeholder contributions are lower in the Private treatment if the Private treatment is first (93.19 as compared to 98.88 percent of endowment, Mann-Whitney test $p=0.000$ ). To check that our main results are unaffected by this order effect, we exclude those 40
} 
Figure 4 shows contribution data across rounds. ${ }^{18}$ Stakeholder contributions in all treatments (the dashed lines) are close to the endowment. This is expected because the Stakeholder's return from the public good is greater than his return from the private good. ${ }^{19}$ Non-Stakeholder contributions for each treatment are lower but positive in all rounds. These contributions show the downward trend usually seen in public goods games. Bachelor contributions in the Ineligible treatment are well below contributions in the other treatments and do not decline across the rounds.

Contributions by non-Stakeholders in the Private treatment compare well to previous research using linear public goods games with similar symmetric “prices of giving." NonStakeholder contributions start at $41 \%$ in round 1 and end at $21 \%$ in round 10 , averaging $33 \%$ across all rounds. In the final round, $47 \%$ of non-Stakeholders make positive contributions. In Ledyard's (1995) survey of public goods game results, first period contributions range from $31 \%-68 \%$ of endowment, and final period contributions range from 9\%-19\% of endowment.

Results from asymmetric-return public goods games are difficult to compare because of differences in payoff structure. In a one-shot game with asymmetric returns, subjects with lower marginal per capita returns in somewhat similar treatments gave $20 \%$ on average in Goeree et al.

subjects who were in the Private treatment first and all results still hold. Further evidence that our results are robust to these order effects come from parametric tests that control for order. In sum, these analyses give us confidence that our results are not caused by treatment order or cross-treatment contamination, so we present results pooling all the data.

${ }^{17}$ In some treatment-order combinations, we see a small correlation between group members' non-Stakeholder contributions in an earlier treatment and a subject's non-Stakeholder contributions in later treatments. This could be caused by contagion, as discussed in footnote 11 . However, this could merely reflect the fact that both of these variables should be correlated with a subject's inherent tendency to contribute. If contagion exists, the effect does not invalidate our results. Treatment effects should be either unaffected or diminished, and our reciprocity result is within-subject-within-treatment so should be unaffected.

${ }^{18}$ The round numbers used in Figure 4 indicate the round number within that treatment. Since data are pooled across orders, the first round of a given treatment (e.g. Private) is also pooled across all orders. This means that round one is behavior in the first round, even though that might not be the subjects first round overall (e.g. if Private was the second or third treatment).

${ }^{19}$ Contributions are not strictly $100 \%$. This could be caused by subject error or myopic inequity aversion. 
(2002), 22.5\% in Reuben and Riedl (2009), and 18\% in Glöckner et al. (2011). These results give us confidence that our overall results are in line with previous work, despite the asymmetry of payoffs.

\subsection{Treatment Effects}

Recall that the main difference between the Private and Public treatments is that the Public treatment opens the door to targeted direct reciprocity, indirect reciprocity, and strategic self-interest. Thus, we can test whether these forces increase the provision of a public good simply by determining whether non-Stakeholder contributions are higher in the Public treatment than they are in the Private treatment.

Figure 4 shows that average non-Stakeholder contributions in the Public treatment exceed those in the Private treatment in all rounds. These differences are only statistically significant in a few rounds, but are significant when pooled across rounds. ${ }^{20}$ As shown in Table 1, the average non-Stakeholder contribution is $14.4 \%$ larger in the Public (37.8\% of endowment) than in the Private treatment (33.0\%) and this difference is significant (paired Wilcoxon signed-rank test $p=0.051) .{ }^{21,22}$

Thus, making a small low-cost change in the information structure of the game to allow targeted reciprocity increases cooperation by a modest but significant amount. This increase in

\footnotetext{
${ }^{20}$ Contributions are significantly higher in Public than Private in rounds 1, 3 and 5.

${ }^{21}$ Note that because our design is within subjects, we are using paired statistical tests to take into account the nonindependence across observations when comparing the behavior of the same subjects across treatments (within subjects). Each test uses individuals' behavior averaged across rounds within a treatment, thus removing within group correlation and giving us 120 observations for each test. When we compare behavior across subjects within a treatment, we use non-paired tests.

${ }^{22}$ If we use a very strict test in which contributions are averaged to the group level and comparisons are done at the group level, the difference between Public and Private contributions is no longer significant (Wilcoxon rank-sum test $p=0.471$ ).
} 
contributions compares well to the effect of other public goods institutions that manipulate information on the contributions of others. ${ }^{23}$ In our setting, information provision enables targeted reciprocity to occur. The increase in contributions may be less costly on net than other institutional changes, such as punishment, even though some of these may yield greater increases. $^{24}$

We now turn to behavior in the Ineligible treatment. Table 1 shows that Bachelors contribute significantly less (23.4\% of endowment) than they did in the Private $(29.9 \%)$ or Public (37.6\%) treatments (paired Wilcoxon signed-rank test $p=0.043$ and $p=0.020$, respectively). It also shows that Bachelors give significantly less than non-Bachelor non-Stakeholders do in the Ineligible treatment (36.0\% of endowment, Mann-Whitney test $p=0.007$ ). However, if Bachelors' contributions are compared to non-Bachelor non-Stakeholder contributions after the non-Bachelors' last Stakeholder stint (21.9\% of endowment) the levels are not significantly different (Mann-Whitney test $p=0.794)$. Note that non-Bachelor contributions decline across rounds while Bachelor contributions do not.

The low contributions of Bachelors, however, are not caused by idiosyncrasies of those subjects who were randomly assigned to be Bachelors. Bachelors in the Ineligible treatment contribute no differently in the Private and Public treatments as compared to those who were not

\footnotetext{
${ }^{23}$ Simply reporting disaggregated individual contributions, as in our Private treatment, rather than total contributions, increased contributions by $21 \%$ in Sell and Wilson (1991) but had no effect in Croson (2001). Revealing donors' contributions to each other increases contributions to external charities by $10 \%$ in Soetevent's (2005) study of church collections, but only for external causes and only temporarily. Andreoni and Petrie (2004) find an increase in giving of 59\% when subjects see a photograph and contribution history for each group member, but there is no significant increase when only a photograph or (most relevantly) only contribution history is revealed.

${ }^{24}$ Costly punishment, another tool of interest in public good provision, has generally been found to increase giving by a large amount but often decreases efficiency overall because of the cost of punishment. An important paper in this area is Fehr and Gächter (2000), and Bochet et al. (2006) contains a useful discussion of the literature. Nonmonetary "punishment" has also been studied, for example, with the use of social disapproval in Masclet et al. (2003) and Carpenter and Seki (2011). However, while social disapproval increased contributions by $37 \%$ in the former, its effects in the latter were mixed and contributions actually decreased for some populations.
} 
Bachelors. $^{25}$ The low contributions of Bachelors in the Ineligible treatment may be caused by several factors. First, Bachelors may feel a weakened urge to conform to a contribution norm because of their different role in the group. Second, their reduced earnings potential may render them less willing to trade off their payoff to benefit others. We explore Bachelors' behavior in more detail in the section on indirect reciprocity.

Additionally, we might think that for non-Bachelors, shrinking the "circle of reciprocity" to four people and adding a public good beneficiary who is outside that circle might dampen contributions. It does not. There is no difference between non-Bachelor non-Stakeholders' contributions in the Ineligible treatment (36.0\% of endowment) and their behavior in the Private (33.8\%) and Public (37.8\%) treatments (paired Wilcoxon signed-rank test $p=0.233$ and $p=0.410$, respectively).

Finally, Figure 5 shows the cumulative distribution of non-Stakeholder contributions pooled across rounds of all sessions. In treatments that allow for targeted direct reciprocity (Public, non-Bachelors in Ineligible), the distribution lies to the right of the treatment where the door to direct reciprocity is closed (Private). That is, there is a first-order shift in the distribution when direct reciprocity is possible. Bachelors, however, give zero tokens more often in the Ineligible than in the Private (paired Wilcoxon signed-rank test $p=0.007$ ) and the Public $(p=0.014)$ treatments. The distribution of contributions for all treatments and roles lie to the right of that of Bachelors in the Ineligible treatment. Also, in the Public treatment, subjects give 20

\footnotetext{
${ }^{25}$ Non-Stakeholder contributions in the Private treatment are not statistically different between subjects who were Bachelors in the Ineligible treatment and subjects who were not (Mann-Whitney test $p=0.507$ ). Similarly, in the Public treatment, Bachelors and non-Bachelors do not give differently (Mann-Whitney test $p=0.653$ ). Subjects who were Bachelors in an early treatment may give less as non-Stakeholder in later treatments than do those who had been non-Bachelors, but this is only significant if the Ineligible treatment is first and if we compare only to the second treatment contributions (15.8\% versus 37.9\% of endowment, Mann-Whitney $p=0.038$ ).
} 
tokens more often than in the Private $(p=0.021)$ and Ineligible ( $p=0.098$ for Bachelors, $p=0.041$ for non-Bachelors) treatments.

\subsection{Direct Reciprocity and Other-Regarding Preferences}

We next look at direct reciprocity, i.e. responsiveness to the current Stakeholder's past behavior. We will first examine reciprocal acts that could either be strategic or rooted in otherregarding preferences, and then we will isolate reciprocity rooted in the latter. To do this, we use nonparametric within-subject tests of aggregate statistics and regression analysis. For each person, we examine whether, as non-Stakeholder, he gave more to the public good on average in rounds in which the current Stakeholder was previously generous to him as compared to rounds in which the current Stakeholder was previously ungenerous. Stakeholder past generosity is determined by the current Stakeholder's average contribution to the public good in rounds in which this subject was the Stakeholder.

To illustrate this approach, assume that subject $i$ is assigned position $\mathrm{A}$ and $j$ is assigned B. Then $i$ is Stakeholder in rounds 1 and 6, and $j$ is Stakeholder in rounds 2 and 7. In round 2, $i$ will remember how generous $j$ was in round 1. "Stakeholder past generosity" will be $j$ 's contribution in round 1. In round 7, when $j$ is Stakeholder, our measure of "Stakeholder past generosity" for $i$ would be the average of $j$ 's contributions in rounds 1 and 6 when $i$ was Stakeholder.

We look first at the effects of generosity using nonparametric tests. To do so, we define a "generosity threshold" $\bar{g}$ such that a group member whose cumulative average contributions in past rounds in which this subject had been Stakeholder are greater than this amount 
$g_{\text {it-cum-avg }} \geq \bar{g}$ are called generous. For each subject, we calculate his average contribution across

all rounds when facing a Stakeholder whose past generosity meets this threshold and his average contribution when facing a Stakeholder whose past generosity does not. We tried many thresholds, including $\bar{g}=6,8,10,12,15$, and 19 tokens and an endogenous threshold calculated as the group's current cumulative average contribution. ${ }^{26}$ All yielded the same qualitative and significant results. We report results from a threshold of $\bar{g}=10$ tokens (50\% of endowment). We choose to report results from this threshold as it seems to be a reasonable threshold for generosity and one subjects may have mind. ${ }^{27}$

A subject displays reciprocal behavior if he gives more when facing a previouslygenerous Stakeholder than when facing a previously-ungenerous Stakeholder. Table 2 presents averages of these measures in Panel I. In all treatments in which it is possible to attribute previous generous and ungenerous acts to a particular group member, generosity is rewarded: subjects give more to a previously-generous Stakeholder than to a previously un-generous Stakeholder (Public treatment $41.9 \%$ as compared to $27.1 \%$ of endowment, paired Wilcoxon signed-rank test $p=0.000$; Ineligible treatment $41.2 \%$ as compared to $23.9 \%$ of endowment, paired Wilcoxon signed-rank test $p=0.000) .{ }^{28}$ As a placebo test, in the treatment in which previous generosity cannot be attributed to a particular individual, it is not rewarded (in the Private treatment, $27.6 \%$ was given to previously-generous Stakeholders as compared to $29.2 \%$

\footnotetext{
${ }^{26}$ Readers who are concerned about the within-subjects design or intra-group correlation should note that this test relies on an individual subject treating members of his group (in a single treatment) in two different ways. Thus this result should be robust to either of those concerns.

${ }^{27}$ To clarify further how the threshold works, suppose that a group contains only subjects $i, j$, and $k$. Subject $j$ gave 15 tokens every time $i$ was Stakeholder, and $k$ always gave 2 tokens. Subject $i$ 's average contribution to a generous Stakeholder is his average contribution when $j$ was Stakeholder, and his average contribution to an ungenerous Stakeholder is his average contribution when $k$ was Stakeholder.

${ }^{28}$ Using a very strict test in which the group is the unit of observation rather than the individual subject, this reciprocity result still holds: while there is still no significant difference between what subjects give to a generous and ungenerous Stakeholder in the Private treatment (one-tailed $t$-test $p=0.795$ ), subjects give significantly more to a generous than an ungenerous Stakeholder in both the Public $(p=0.000)$ and Ineligible $(p=0.000)$ treatments.
} 
to previously-ungenerous Stakeholders, paired Wilcoxon signed-rank test $p=0.773$ ). We would not expect rewards to generous behavior in the Private treatment because subjects cannot tell who is Stakeholder or what the current Stakeholder did in the past. In the Public and Ineligible treatments, however, subjects give over 50\% more to previously-generous Stakeholders than they give to previously-ungenerous Stakeholders..$^{29,30}$

Table 3 confirms these results with regressions. The first three columns show panel OLS fixed effects regressions of non-Stakeholder contributions on the current Stakeholder's past generosity, cumulative average group contributions, round number and whether the subject is past his last Stakeholder stint. ${ }^{31}$ All regressions control for individual subject fixed effects, and errors are clustered by group. The coefficients on past generosity are significant and positive in the Ineligible and Public treatments, but not in the Private treatment. Group average contributions do not significantly influence contributions; the linear trend for round numbers is significant and negative only for one treatment (Ineligible). While one might expect a discontinuous dropoff in contributions after a subject's last Stakeholder stint, we only see this effect in the Private treatment.

\footnotetext{
${ }^{29}$ Recall that subjects could respond to past actions of the current Stakeholder and the current non-Stakeholders, although their contributions benefit the former three times as much as the latter. If subjects were responding to nonStakeholders in this way, this would attenuate our within-subject measure of responsiveness to Stakeholder history.

${ }^{30}$ Misplaced or maladaptive reciprocal behavior could happen if subjects believe their behavior in an early treatment can affect outcomes in later treatments. Our finding of reciprocity is robust to this phenomenon because responsiveness is still significant in the Public treatment even when the Public treatment is the last treatment experienced.

${ }^{31}$ Non-Stakeholder contributions in each round $g_{i t}$ are regressed on characteristics of that round, including $h_{i k t}$ (a summary of the current Stakeholder $k$ 's past generosity toward subject $i$ : here, the current Stakeholder's cumulative average contributions when subject $i$ was Stakeholder) and $\mathbf{X}_{i t}$ (other variables): $g_{i t}=a+b h_{i k t}+\mathbf{C X}_{i t}+{ }_{i t}$. If direct reciprocity or strategic self-interest is important, $b$ (the coefficient on $h_{i k t}$ ) should be positive in both the Public and Ineligible treatments. In the Private treatment, $b$ should be zero. Group-level conditional cooperation could bias this coefficient upward, so we counteract that bias by including a control for group generosity in $\mathbf{X}_{i t}$ : the group's cumulative average non-Stakeholder contribution in past rounds. For each subject in each round, this measure excludes his own past contributions and those of the current Stakeholder. In the Ineligible treatment, this group measure also excludes data from the Bachelor (although the same results obtain if the Bachelor's data is included).
} 
Another way to look at direct reciprocation is to examine responsiveness, the difference between the amount given to a generous Stakeholder and the amount given to an ungenerous Stakeholder, between treatments. Responsiveness is greater in both the Public (14.8\% of endowment) and Ineligible (17.3\% of endowment) treatments than in the Private (-1.6\% of endowment) treatment (paired Wilcoxon signed-rank test $p=0.000$ and $p=0.000$, respectively). Responsiveness does not differ between the Public and Ineligible treatments $(p=0.966)$. These results are confirmed in Table 4, which shows a stacked regression of responsiveness controlling for individual fixed effects and group-level correlation. Subjects are significantly more likely to give more to a "nice" Stakeholder in the Public and Ineligible treatments. These tests give us evidence of directly reciprocal behavior, although this behavior may be rooted in strategic selfinterest.

We dispose of strategic concerns by looking for reciprocal giving after a person has passed his last Stakeholder stint. For example, again assume that subject $i$ was Stakeholder in rounds 1 and 6 and $j$ was Stakeholder in rounds 2 and 7. Assume no further fundraising rounds follow. If $j$ was kind to $i$ in rounds 1 and 6 , will $i$ reciprocate in round 7? If $i$ is purely strategic, he has little to gain, so he should not contribute and therefore not reciprocate. This is also the logic that was used in one test of reciprocity rooted in other-regarding preferences in Cabral et al. (2012).

We test for non-strategic reciprocity by constructing statistics of each subject's average contribution to previously generous and ungenerous Stakeholders in rounds after this subject's last Stakeholder stint. These results, in Panel II of Table 2, show that subjects are not simply motivated by strategic concerns. Other regarding preferences are more strongly at play. Subjects in the Public treatment continue to discriminate between generous Stakeholders (to whom they 
give $30.0 \%$ of endowment) and ungenerous Stakeholders (16.9\%) even after they have no strategic motive to do so. This difference is statistically significant (paired Wilcoxon signed-rank test $p=0.026$ ). In the Ineligible treatment, the sample size is reduced because only non-Bachelors are considered and the treatment has fewer rounds. Because of this reduced power, discrimination in late rounds is not statistically significant, although the difference is in the same direction.

These results are confirmed in Table 3 . The last three columns repeat the regressions in the first three columns but only use contributions in rounds after the last Stakeholder stint, when the subject has no strategic incentive to reward past good behavior. The coefficient on past generosity is significant and positive in the Public treatment, and the direction is the same in the Ineligible treatment, but it is not significant.

\subsection{Indirect Reciprocity}

We now examine evidence of indirect reciprocity. We define this type of positive reciprocity as the action of a disinterested party who rewards one agent for past generosity toward another agent. This kind of indirect reciprocity cannot be tested by looking at the responsiveness of a subject who has the opportunity to be Stakeholder because he is not disinterested. He can benefit from fostering a norm of cooperation and reciprocation. The behavior of Bachelors in the Ineligible treatment gives us a clean test of indirect reciprocity. These subjects will never be Stakeholder, so they can never benefit directly from targeting 
generosity. Therefore, direct reciprocity and strategic self-interest cannot drive Bachelor giving. Bachelors can't even receive great benefits from conditional cooperation. ${ }^{32}$

We have shown that Bachelors give significantly less than non-Stakeholders in the Ineligible treatment and less than they themselves gave in other treatments. Bachelors also behave reciprocally when they are part of the circle of reciprocity, in that they have positive responsiveness in the Public treatment (giving $35.0 \%$ of endowment to previously generous Stakeholders and $22.3 \%$ of endowment to previously ungenerous Stakeholders, significantly different with paired Wilcoxon signed-rank $p=0.004)$. However, Bachelors in the Ineligible treatment do not give more when facing previously generous Stakeholders. They give $21.9 \%$ of endowment when facing previously generous Stakeholders and 25.5\% when facing previously ungenerous Stakeholders. ${ }^{33}$ These levels are not significantly different (paired Wilcoxon signedrank $p=0.823$ ). Therefore, indirect reciprocity does not seem to be a motivator in this setting. ${ }^{34}$

This result is intriguing because other studies have found evidence of indirect reciprocity, even in cases of positive rather than negative reciprocity (e.g., Engelmann and Fischbacher, 2009; Seinen and Schram, 2006). The re-matching structure of those experiments allows subjects to have a financial interest in the group's overall cooperation and propensity to reciprocate because they would eventually be direct beneficiaries. Subjects, therefore, are not as

\footnotetext{
${ }^{32}$ Bachelors do benefit from a cooperative group, since their payoff is a function of group contributions, however, there is no way for a Bachelor to directly benefit by being nice to previously generous Stakeholder.

${ }^{33}$ For Bachelors, the current Stakeholder's past generosity is defined by how much the current Stakeholder gave on average as non-Stakeholder in all past rounds.

${ }^{34} \mathrm{We}$ also checked to see if contributions were affected by past generosity to self and past generosity to others. Current Stakeholder past contribution to others is indeed significant in a regression; however, we caution against any strong interpretation of this for two reasons. First, the correlation between Stakeholder past generosity to self and Stakeholder past generosity to others is high in all cases (although inclusion of this variable does not greatly affect the coefficient on Stakeholder past generosity to self). Second, and more importantly, this coefficient cannot be interpreted as indirect reciprocity because a person who has been and will be Stakeholder may see someone else's generosity even in a round in which this subject is not Stakeholder as a signal of how this group member will behave when this subject IS Stakeholder, and thus he may have a great interest in promoting good behavior. Thus, a person in this position is far less disinterested than a Bachelor.
} 
disinterested as our Bachelors are. Both conditions are valid settings in which to examine cooperation. However, our results align more closely with the "bystander" interpretation of indirect reciprocity.

\section{Conclusions}

Favor trading is a natural element of social networks. Grassroots fundraising and other institutions can achieve pro-social ends by taking advantage of the desire to be nice to those who have been nice to you. In an experiment that allows different forms of reciprocity to be turned on and off, we explore the power of favor trading and the underlying reciprocal motivations through which institutions such as grassroots fundraising may work. In our setting, favor trading increases cooperation by $14.4 \%$. This result demonstrates that groups like Olson's (1965) "privileged groups," which contain members who have a dominant strategy of contributing, can be structured to further pro-social ends.

Our results also provide a new window into reciprocity. We find clear evidence of direct reciprocal giving that is non-strategic. ${ }^{35}$ While some studies have found direct reciprocity in laboratory institutions like the investment game (e.g., Berg et al., 1995), others have criticized the abstraction of those institutions (e.g., List, 2006). The presence of direct reciprocity in our slightly richer setting may be a good step in understanding how institutions outside of the lab can take advantage of these motives for social gain. In particular, our reciprocity findings are a complement to the result of DellaVigna et al. (2012) that social pressure is important in door-todoor fundraising.

\footnotetext{
${ }^{35}$ Cabral, Ozbay, and Schotter (2012) find that strategic forces are strong in their repeated veto game. As they note, while contributions do decline in final rounds (indicating that strategic concerns matter), they do not decline to zero, so other-regarding preferences play a role there as well.
} 
Intriguingly, we find no evidence of indirect reciprocity in our Ineligible treatment. While most experiments that examine indirect reciprocity allow actors to directly benefit from an increased tendency to cooperate within the group, we strip our Bachelor of strong incentives to foster cooperative norms. When given the costly chance to reward a kind act without the possibility of future direct reciprocation, our Bachelors do not provide such rewards. This also stands in contrast to third party punishment/reward games (e.g. Fehr and Fischbacher, 2004; Almenberg et al., 2011) in which disinterested parties will pay to punish bad behavior or reward good behavior. In those games, it is arguably costlier for the third party to take action. It is possible that one difference is that in those games the disinterested third party's attention is totally focused on the decision to punish or reward, while in ours such an action would have to occur through a change in contribution behavior.

Reciprocity has the power to increase pro-social behavior and therefore efficiency. Favor trading can be harnessed in very low-cost ways through simple information provision. Charitable organizations seem to recognize the power of reciprocal giving in social networks as they have developed vehicles like Facebook Cause promotion and custom donor-created websites like DonorPages.

Will our finding of increased efficiency through reciprocal giving translate to non-lab social environments? Or will people tend to either contribute only to their own pet causes or to offset increased contributions to a friend's charity by reduced contributions to their own charities? The linear nature of the public goods in our experiment, while important in presenting a simple choice to subjects, clouds this generalization. Charities' interest in social fundraising does not necessarily imply that socially-elicited contributions to one organization do not crowd out contributions to other organizations. Field studies could provide an answer to this question, 
but it seems likely that most theories of other-regarding preferences would imply that if there is such crowd-out, it is incomplete. 


\section{References}

Almenberg, Johan, Dreber, Anna, Apicella, Coren L. and Rand, David G., 2011, Third Party Reward and Punishment: Group Size, Efficiency and Public Goods. In: Nicholas M. Palmetti and Jennifer P. Russo (Ed.), Psychology of Punishment. Nova Publishing, pp. 73-92.

Andreoni, James, William Harbaugh, and Lise Vesterlund. 2003. "The Carrot or the Stick: Rewards, Punishments, and Cooperation." American Economic Review, 93:3, pp. 893-902.

Andreoni, James and Ragan Petrie. 2004. "Public goods experiments without confidentiality: A glimpse into fund-raising." Journal of Public Economics, 88:7-8, pp. 1605-23.

Berg, Joyce, John W. Dickhaut, and Kevin A. McCabe. 1995. "Trust, Reciprocity, and Social History." Games and Economic Behavior, 10:1, pp. 122-42.

Bochet, Olivier, Talbot Page, and Louis Putterman. 2006. "Communication and Punishment in Voluntary Contribution Experiments." Journal of Economic Behavior and Organization, 60:1, pp. 11-26.

Cabral, Luis, Ozbay, Erkut Y. and Schotter, Andrew, 2012. "Intrinsic and instrumental reciprocity: An experimental study." Working paper. New York University

Carpenter, Jeffrey and Erika Seki. 2011. "Do Social Preferences Increase Productivity? Field Experimental Evidence from Fishermen in Toyama Bay." Economic Inquiry, 49:2, pp. 612-630.

Charness, Gary and Matthew Rabin. 2002. "Understanding Social Preferences with Simple Tests." Quarterly Journal of Economics, 117:3, pp. 817-69.

Chaudhuri, Ananish, 2011. "Sustaining Cooperation in Laboratory Public Goods Experiments: A Selective Survey of the Literature." Experimental Economics, 14(1), 47-83.

Cox, James C. 2004. "How to Identify Trust and Reciprocity." Games and Economic Behavior, 46:2, pp. 260-81.

Cox, James C., Daniel Friedman, and Vjollca Sadiraj. 2008. "Revealed Altruism." Econometrica, 76:1, pp. 31-69.

Croson, Rachel T. A. 2001. "Feedback in Voluntary Contribution Mechanisms: An Experiment in Team Production," in Research in experimental economics. Volume 8. R. Mark Isaac ed: Amsterdam; New York and Tokyo: Elsevier Science, JAI, pp. 85-97. 
DellaVigna, Stefano, List, John A. and Malmendier, Ulrike, 2012. "Testing for Altruism and Social Pressure in Charitable Giving." Quarterly Journal of Economics, 127(1), 1-56.

Dreber, Anna, Fudenberg, Drew and Rand, David G., 2011, "Who Cooperates in Repeated Games?" Working paper.

Engelmann, Dirk and Urs Fischbacher. 2009. "Indirect reciprocity and strategic reputation building in an experimental helping game." Games and Economic Behavior, 67:2, pp. 399-407.

Fehr, Ernst and Fischbacher, Urs, 2004. Third-party punishment and social norms. Evolution and Human Behavior, 25:2, pp. 63-87.

Fehr, Ernst and Simon Gächter. 2000. "Cooperation and Punishment in Public Goods Experiments." The American Economic Review, 90:4, pp. 980-94.

Fehr, Ernst, George Kirchsteiger, and Arno Riedl. 1993. "Does Fairness Prevent Market Clearing? An Experimental Investigation." Quarterly Journal of Economics, 108:2, pp. 437-59.

Fischbacher, Urs. 2007. "z-Tree: Zurich Toolbox for Ready-Made Economic Experiments." Experimental Economics, 10:2, pp. 171-78.

Fischbacher, Urs, Simon Gachter, and Ernst Fehr. 2001. "Are People Conditionally Cooperative? Evidence from a Public Goods Experiment." Economics Letters, 71:3, pp. 397-404.

Gächter, Simon. 2007. "Conditional cooperation: Behavioral regularities from the lab and the field and their policy implications," in Economics and Psychology. A Promising New CrossDisciplinary Field. Bruno S. Frey and Alois Stutzer eds. Boston, MA: The MIT Press.

Girl Scouts of the USA. 2011. "Girl Scout Cookies and Learning Life Skills." http://www.girlscouts.org/program/gs_cookies/, retrieved January 2011.

Glöckner, Andreas, Bernd Irlenbusch, Sebastian Kube, Andreas Nicklisch, and Hans T. Normann. 2011. " Leading with(out) Sacrifice? A Public-Goods Experiment with a Privileged Player." Economic Inquiry, 49:2, pp. 591-597.

Gneezy, Uri and John A. List. 2006. "Putting Behavioral Economics to Work: Testing for Gift Exchange in Labor Markets Using Field Experiments." Econometrica, 74:5, pp. 1365-84.

Goeree, Jacob, Charles Holt, and Susan Laury. 2002. "Private Costs and Public Benefits: Unraveling the Effects of Altruism and Noisy Behavior." Journal of Public Economics, 83:2, pp. 255-76. 
Houser, Daniel, Erte Xiao, Kevin McCabe, and Vernon Smith. 2008. "When Punishment Fails: Research on Sanctions, Intentions and Non-cooperation." Games and Economic Behavior, 62:2, pp. 509-32.

Isaac, R. Mark and Norton, Douglas, Forthcoming. "Endogenous institutions and the possibility of reverse crowding out." Public Choice.

Jackson, Matthew O., Rodriguez-Barraquer, Tomas and Tan, Xu, 2012. "Social Capital and Social Quilts: Network Patterns of Favor Exchange." American Economic Review, 102(5), 18571897.

Klein, Daniel B. 1990. "The Voluntary Provision of Public Goods? The Turnpike Companies of Early America." Economic Inquiry, 28:4, pp. 788-812.

La Ferrara, Eliana, 2003. "Kin Groups and Reciprocity: A Model of Credit Transactions in Ghana." American Economic Review, 93(5), 1730-1751.

Ledyard, John O. 1995. "Public goods: A survey of experimental research," in The Handbook of Experimental Economics. John H. Kagel and Alvin E. Roth eds. Princeton, NJ, USA: Princeton University Press.

List, John A. 2006. "The Behavioralist Meets the Market: Measuring Social Preferences and Reputation Effects in Actual Transactions." Journal of Political Economy, 114:1, pp. 1-37.

Long, Stephen H. 1976. "Social Pressure and Contributions to Health Charities." Public Choice, 28:Winter, pp. 55-66.

Masclet, David, Charles Noussair, Steven Tucker, and Marie-Claire Villeval. 2003. "Monetary and Nonmonetary Punishment in the Voluntary Contributions Mechanism." American Economic Review, 93:1, pp. 366-280.

Meer, Jonathan and Rosen, Harvey S., 2011. "The ABCs of charitable solicitation." Journal of Public Economics, 95(5-6), 363-371.

Milinski, Manfred, Dirk Semmann, and Hans-Jurgen Krambeck. 2002. "Reputation helps solve the "tragedy of the commons'." Nature, 415:6870, pp. 424-26.

Nowak, Martin A. and Karl Sigmund. 2005. "Evolution of indirect reciprocity." Nature, 437:7063, pp. 1291-98.

Olson, Mancur., 1965, The logic of collective action: public goods and the theory of collective action. Harvard University Press, Cambridge, Mass. 
Preston, Caroline. 2010. "Charities Must Find Multiple Ways to Persuade People of Different Generations to Give, Study Finds." The Chronicle of Philanthropy: Washington, DC.

Rabin, Matthew. 1993. "Incorporating Fairness into Game Theory and Economics." American Economic Review, 83:5, pp. 1281-302.

Reuben, Ernesto and Riedl, Arno, 2009. "Public Goods Provision and Sanctioning in Privileged Groups." Journal of Conflict Resolution, 53:1, pp. 72-93.

Reuben, Ernesto and Suetens, Sigrid, 2012a. "Revisiting strategic versus non-strategic cooperation." Experimental Economics, 15:1, pp. 24-43.

Reuben, Ernesto and Suetens, Sigrid, 2012b, "On the cognitive and motivational components of reciprocity." Working paper.

Seinen, Ingrid and Arthur Schram. 2006. "Social Status and Group Norms: Indirect Reciprocity in a Repeated Helping Experiment." European Economic Review, 50:3, pp. 581-602.

Sell, Jane and Rick K. Wilson. 1991. "Levels of information and contributions to public goods." Social Forces, 70:1, pp. 107-24.

Sobel, Joel. 2005. "Interdependent Preferences and Reciprocity." Journal of Economic Literature, 43:2, pp. 392-436.

Soetevent, Adriaan R. 2005. "Anonymity in Giving in a Natural Context--A Field Experiment in 30 Churches." Journal of Public Economics, 89:11-12, pp. 2301-23.

Stanca, Luca. 2009. "Measuring indirect reciprocity: Whose back do we scratch?" Journal of Economic Psychology, 30:2, pp. 190-202.

Trivers, Robert L. 1971. "The evolution of reciprocal altruism." The Quarterly Review of Biology, 46:1, pp. 35-57. 


\section{Figures and Tables}

\begin{tabular}{|c|c|c|c|c|c|c|c|}
\hline \multicolumn{8}{|c|}{ You are now: MAKING YOUR CONTRIBUTION FOR ROUND 3} \\
\hline \multicolumn{8}{|c|}{ Your Letter Code: D Stakeholder: C } \\
\hline \multicolumn{8}{|c|}{ CONTRIBUTIONS TO THE GROUP FUND } \\
\hline & & & & $\underline{\text { YOU }}$ & & & \\
\hline & & & Stakeholder & & & & \\
\hline & $\underline{\mathbf{A}}$ & $\underline{\mathbf{B}}$ & $\underline{\mathbf{c}}$ & $\underline{\mathrm{D}}$ & $\underline{E}$ & $\begin{array}{l}\frac{\text { TOTAL TOKENS IN GROUP }}{\text { EUND }} \\
\text { UN }\end{array}$ & MYEARNINGS \\
\hline Round 1 & $\underline{10}$ & 6 & 2 & 14 & 18 & 50 & $\$ 0.62$ \\
\hline Round 2 & 19 & 11 & 3 & 7 & 15 & 55 & $\$ 0.81$ \\
\hline Round 3 & & & *askt* & & & & \\
\hline Round 4 & & & & thetst & & & \\
\hline Round 5 & & & & & 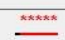 & & \\
\hline Round 6 & $x+x+x+x$ & & & & & & \\
\hline Round 7 & & 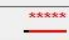 & & & & & \\
\hline Round 8 & & & 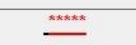 & & & & \\
\hline Round 9 & & & & $\stackrel{* * \star * x *}{n}$ & & & \\
\hline Round 10 & & & & & 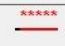 & & \\
\hline \multicolumn{8}{|c|}{ staste indicates that this person was/will be Stakeholder in the round indicated } \\
\hline \multicolumn{8}{|c|}{ DECISION PANEL } \\
\hline \multicolumn{8}{|c|}{ How much would you like to put in the GROUP FUND? $(0-20)$} \\
\hline \multicolumn{8}{|c|}{ Your PERSONAL FUND contribution will be 20 minus your GROUP FUND contribution. } \\
\hline \multicolumn{8}{|l|}{ RETURNS: } \\
\hline Personal fund: & \multicolumn{5}{|c|}{$\$ 0.02$ per token to you } & \multicolumn{2}{|c|}{ CLICK TO SUBMIT } \\
\hline Group fund: & \multicolumn{5}{|c|}{$\begin{array}{l}\$ 0.03 \text { per token to Stakeholder } \\
\$ 0.01 \text { per token to non-Stakeholders (including YOU) }\end{array}$} & CLICK TO & SUBMIT \\
\hline
\end{tabular}

Figure 1. Public Treatment Decision Screen 


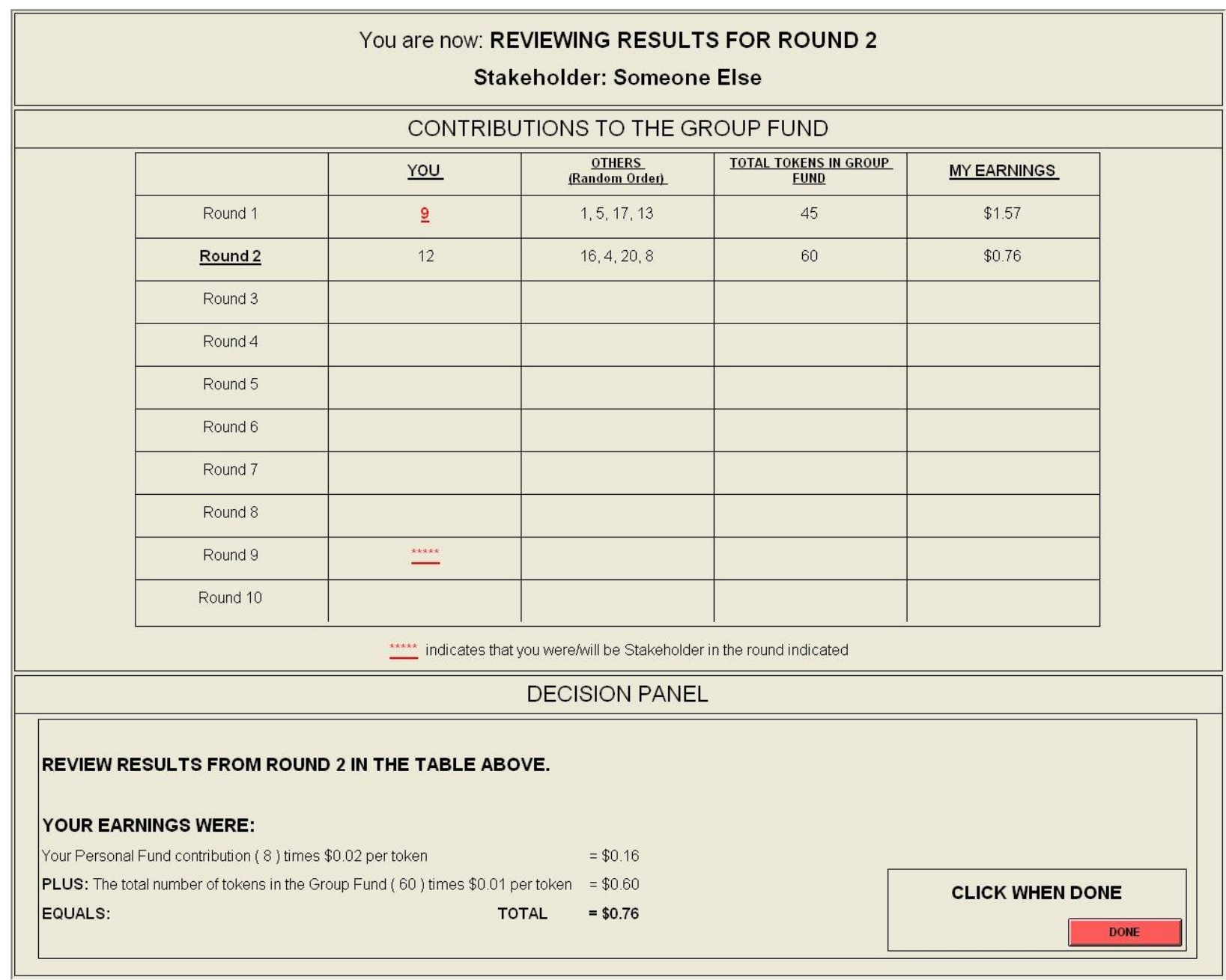

Figure 2. Private Treatment Review Screen 


\begin{tabular}{|c|c|c|c|c|c|c|c|}
\hline \multicolumn{8}{|c|}{ You are now: REVIEWING RESULTS FOR ROUND 2} \\
\hline \multicolumn{8}{|c|}{ Your Letter Code: C Stakeholder: B Ineligible: D } \\
\hline \multicolumn{8}{|c|}{ CONTRIBUTIONS TO THE GROUP FUND } \\
\hline & & & $\underline{\text { YOU }}$ & & & & \\
\hline & & Stakeholder & & Ineligible & & & \\
\hline & $\underline{\mathbf{A}}$ & $\underline{B}$ & $\underline{\mathrm{c}}$ & $\underline{\mathbf{D}}$ & $\underline{E}$ & $\frac{\text { TOTAL TOKENS IN }}{\text { GROUP FUND }}$ & MYEARNINGS \\
\hline Round 1 & 1 & 4 & 2 & 16 & 8 & 31 & $\$ 0.67$ \\
\hline Round 2 & 20 & $\underline{0}$ & 17 & 9 & 3 & 49 & $\$ 0.55$ \\
\hline Round 3 & & & $\underline{x+\infty+\infty}$ & & & & \\
\hline Round 4 & & & & & $\stackrel{x+x+\infty}{*}$ & & \\
\hline Round 5 & statest & & & & & & \\
\hline Round 6 & & 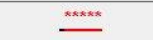 & & & & & \\
\hline Round 7 & & & 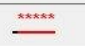 & & & & \\
\hline Round 8 & & & & & 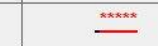 & & \\
\hline \multicolumn{8}{|c|}{ indicates that this person was/will be Stakeholder in the round indicated } \\
\hline \multicolumn{8}{|c|}{ DECISION PANEL } \\
\hline \multicolumn{8}{|c|}{ REVIEW RESULTS FROM ROUND 2 IN THE TABLE ABOVE. } \\
\hline \multicolumn{8}{|c|}{ YOUR EARNINGS WERE: } \\
\hline \multicolumn{4}{|c|}{ Your Personal Fund contribution ( 3 ) times $\$ 0.02$ per token } & $=\$ 0.06$ & & & \\
\hline \multicolumn{4}{|c|}{ PLUS: The total number of tokens in the Group Fund ( 49 ) times $\$ 0.01$ per token } & $=\$ 0.49$ & & \multicolumn{2}{|c|}{ CLICK WHEN DONE } \\
\hline EQUALS: & & & TAL & $=\$ 0.55$ & & & DONE \\
\hline
\end{tabular}

Figure 3. Ineligible Treatment Review Screen 

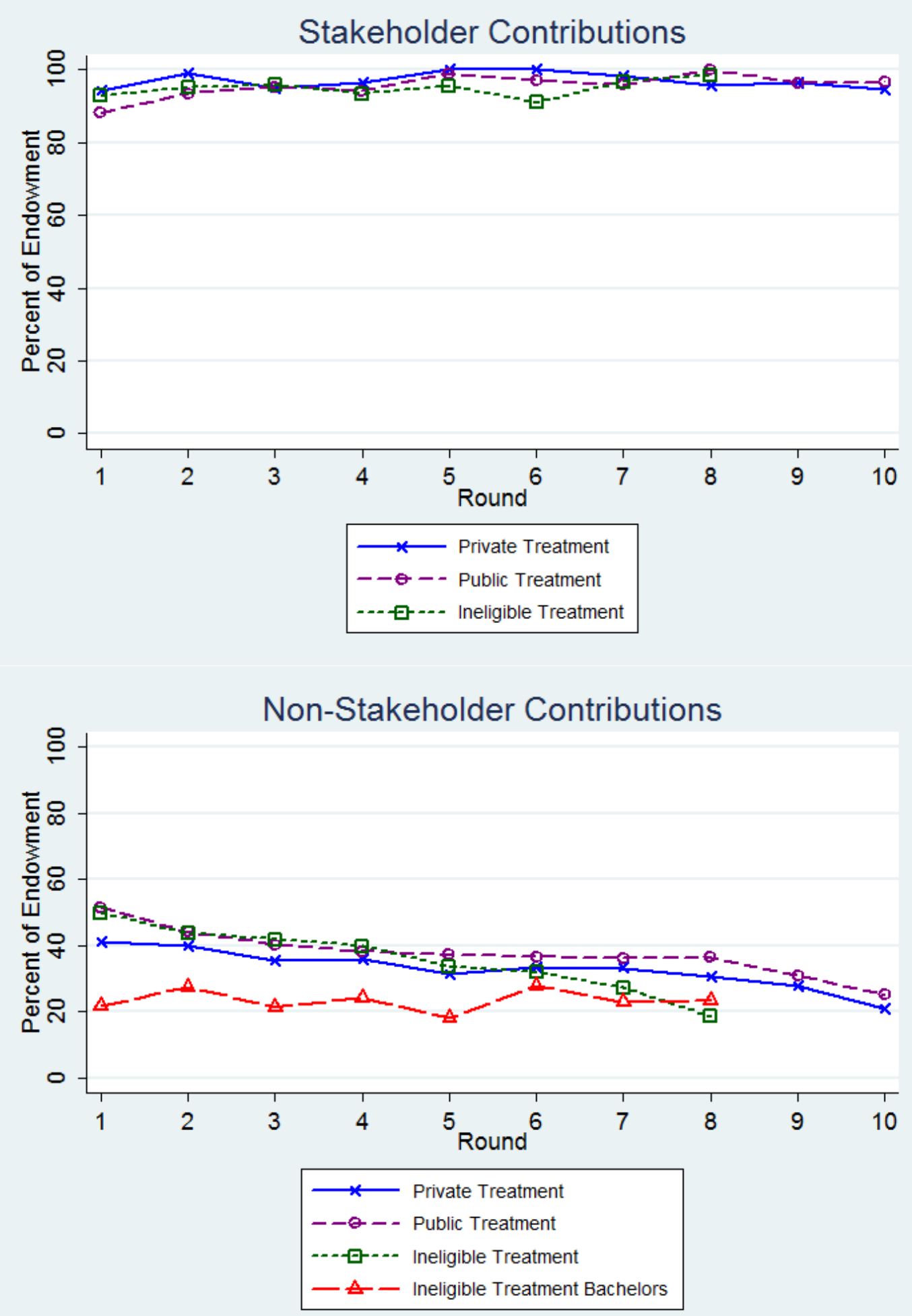

Note: Round numbers indicate round number within a treatment; data pooled across treatment orders

Figure 4. Contributions by Treatment and Role across Rounds (in Percent of Endowment) 

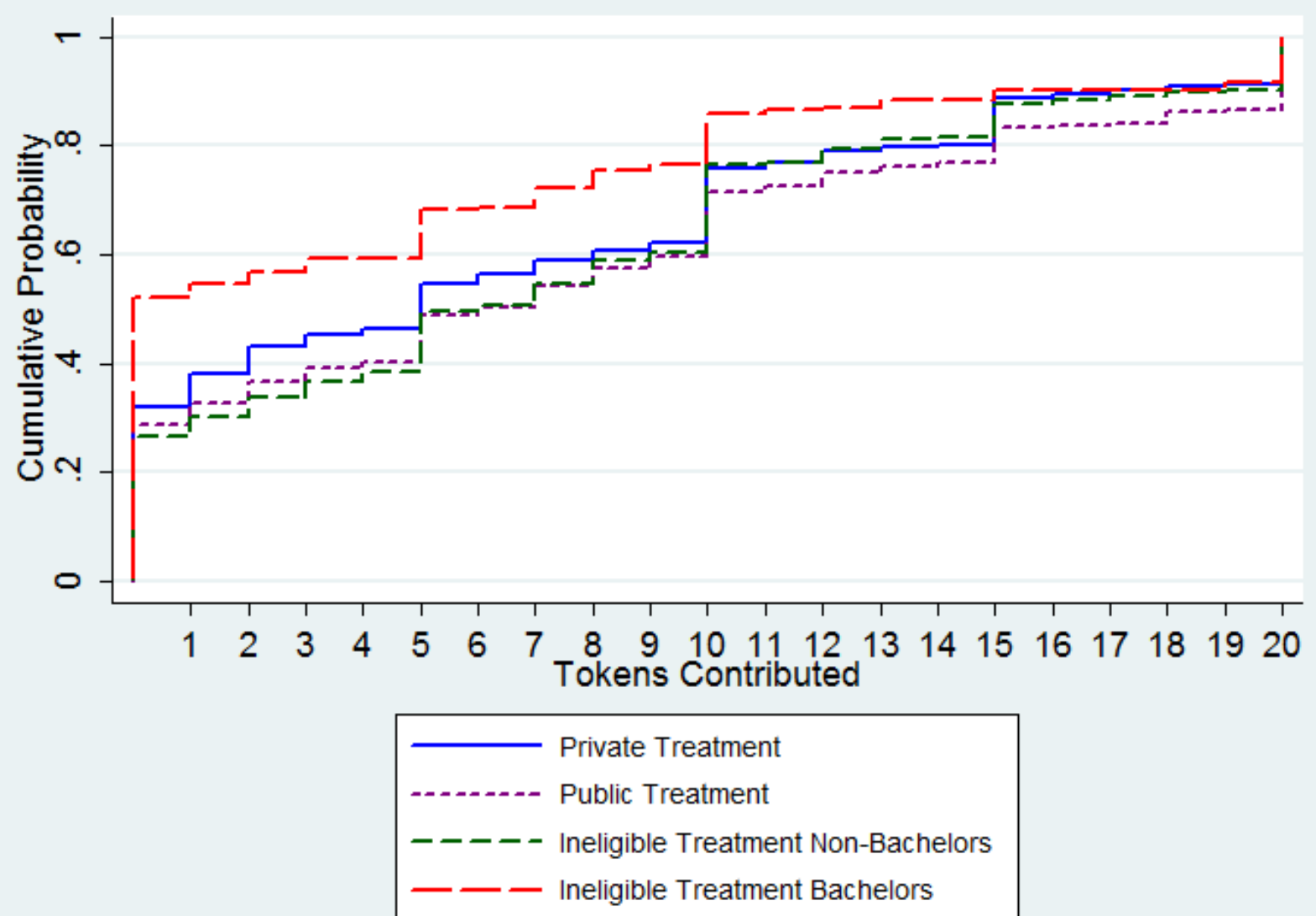

Note: unit of observation is an individual's contribution in a single round; data are pooled across rounds.

Figure 5. Cumulative Distribution of Non-Stakeholder Contribution Amounts (in Tokens) 
Table 1. Average Contributions by Treatment and Role (Percent of Endowment)

\begin{tabular}{lcccc}
\hline Stakeholder & $\begin{array}{c}\text { Non- } \\
\text { Stakeholder }\end{array}$ & $\begin{array}{c}\text { Non- } \\
\text { Stakeholders } \\
\text { who were } \\
\text { Bachelors }\end{array}$ & $\begin{array}{c}\text { Non- } \\
\text { Stakeholders } \\
\text { who were Non- } \\
\text { Bachelors }\end{array}$ \\
\hline Private Treatment & 96.98 & 33.02 & 29.90 & 33.80 \\
& $(10.30)$ & $(25.98)$ & $(26.89)$ & $(25.83)$ \\
\hline Public Treatment & $\mathrm{N}=120$ & $\mathrm{~N}=120$ & $\mathrm{~N}=24$ & $\mathrm{~N}=96$ \\
\hline Ineligible & $(10.63$ & 37.75 & 37.60 & 37.79 \\
Treatment, Non- & $\mathrm{N}=120$ & $(25.93)$ & $(30.42)$ & $(24.86)$ \\
Bachelors & 94.95 & $\mathrm{~N}=120$ & $\mathrm{~N}=24$ & $\mathrm{~N}=24$ \\
\hline Ineligible & $(11.74)$ & $(22.26)$ & $\mathrm{N} / \mathrm{A}$ & 35.96 \\
Treatment, & $\mathrm{N}=96$ & $\mathrm{~N}=96$ & & $(22.26)$ \\
Bachelors & $\mathrm{N} / \mathrm{A}$ & 23.39 & 23.39 & $\mathrm{~N}=96$ \\
\hline
\end{tabular}

Standard deviations in parentheses

Table 2. Non-Stakeholder Contributions by Subject Averaged across Rounds by Stakeholder's Past Generosity toward Subject (in Percent of Endowment)

\begin{tabular}{lccc}
\hline & $\begin{array}{c}\text { Private } \\
\text { Treatment }\end{array}$ & $\begin{array}{c}\text { Public } \\
\text { Treatment }\end{array}$ & $\begin{array}{c}\text { Ineligible Treatment } \\
\text { (excl. Bachelors) }\end{array}$ \\
\hline Panel I: All Rounds & & & \\
\hline Generous stakeholder & 27.57 & 41.92 & 41.22 \\
& $(26.62)$ & $(32.06)$ & $(29.11)$ \\
\hline Ungenerous stakeholder & 29.16 & 27.09 & 23.92 \\
& $(29.59)$ & $(27.63)$ & $(24.08)$ \\
\hline$N$ & 82 & 95 & 75 \\
$p$-value (paired Wilcoxon signed-rank test) & 0.773 & 0.000 & 0.000 \\
\hline
\end{tabular}

Panel II: Only Post Last Stakeholder Stint

\begin{tabular}{lccc}
\hline Generous stakeholder & $\begin{array}{c}\text { Private } \\
\text { Treatment }\end{array}$ & $\begin{array}{c}\text { Public } \\
\text { Treatment }\end{array}$ & $\begin{array}{c}\text { Ineligible Treatment } \\
\text { (excl. Bachelors) }\end{array}$ \\
\hline Ungenerous stakeholder & 14.60 & 30.00 & 26.60 \\
& $(25.70)$ & $(30.99)$ & $(31.98)$ \\
\hline$N$ & 18.60 & 16.93 & 19.30 \\
$p$-value (paired Wilcoxon signed-rank test) & $(29.24)$ & $(27.43)$ & $(27.75)$ \\
\hline
\end{tabular}

Standard deviations in parentheses. Note: Generous stakeholder is one who gave $\geq 10$ on average in past rounds in which subject was a stakeholder. Ungenerous stakeholders gave $<10$ in past rounds. Paired signed-rank test based on average contributions across all subjects within a group when facing a generous or non-generous stakeholder. Standard deviations are in parentheses. N's are less than 120 because some subjects did not face both a generous and an ungenerous Stakeholder. For this reason, we dropped 38 of 120 subjects in Private, 25 of 120 in Public, and 21 of 
96 subjects in Ineligible in Panel I and 41 of 120 in Private, 31 of 120 in Public, and 23 of 96 in Ineligible in Panel II. Additionally, in Panel II, 48 subjects had to be dropped because they had fewer than two rounds remaining after their last Stakeholder stint.

Table 3. OLS Fixed Effects Panel Regression of Non-Stakeholder Contribution (in Percent of Endowment) on Period-Level Covariates, Overall and Post-Last Stakeholder Stint

\begin{tabular}{lcrrrrr}
\hline & Private & Public & Ineligible & $\begin{array}{c}\text { Private } \\
\text { Post-Last }\end{array}$ & $\begin{array}{c}\text { Public } \\
\text { Post-Last }\end{array}$ & $\begin{array}{r}\text { Ineligible } \\
\text { Post-Last }\end{array}$ \\
\hline Stakeholder average past & 0.05 & $0.24^{* * *}$ & $0.23^{* *}$ & -0.02 & $0.21^{*}$ & 0.17 \\
contributions to me & $(0.06)$ & $(0.05)$ & $(0.09)$ & $(0.11)$ & $(0.11)$ & $(0.22)$ \\
Group average & 0.25 & 0.05 & -0.08 & 0.39 & -0.09 & 0.30 \\
contributions & $(0.16)$ & $(0.17)$ & $(0.27)$ & $(0.44)$ & $(0.32)$ & $(0.60)$ \\
Round number & 0.03 & -1.69 & $-2.86 * *$ & $-4.12^{* *}$ & $-5.90^{* * *}$ & $-4.89^{* *}$ \\
& $(0.65)$ & $(1.22)$ & $(1.34)$ & $(1.83)$ & $(1.96)$ & $(2.26)$ \\
Post-last Stakeholder & $-9.66^{* *}$ & -1.66 & -4.85 & & & \\
stint? (dummy) & $(3.86)$ & $(5.05)$ & $(5.40)$ & & & \\
Constant & $22.15^{* * *}$ & $34.65 * *$ & $42.50 * *$ & $48.39 * *$ & $76.14 * * *$ & 42.89 \\
& $(7.48)$ & $(13.68)$ & $(16.18)$ & $(22.93)$ & $(25.80)$ & $(25.08)$ \\
\hline Observations (rounds) & 720 & 720 & 432 & 240 & 240 & 144 \\
Number of subjects & 120 & 120 & 96 & 96 & 96 & 72 \\
$R^{2}$ (within) & 0.037 & 0.115 & 0.192 & 0.061 & 0.140 & 0.079 \\
$F$ & 4.50 & 13.37 & 31.47 & 2.03 & 3.70 & 1.78 \\
\hline Robust standard errors in parentheses; errors are clustered on group; individual fixed effects. * significant at 10\%; & & & &
\end{tabular}

Table 4. Panel Stacked Regression of Average Contribution (in Percent of Endowment) on "Nice Dummy"

\begin{tabular}{lccc}
\hline & Private Treatment & Public Treatment & $\begin{array}{c}\text { Ineligible Treatment } \\
\text { (excl. Bachelors) }\end{array}$ \\
\hline "Nice dummy" & -1.59 & $14.83 * * *$ & $17.30 * * *$ \\
Constant & $(2.72)$ & $(2.68)$ & $(2.72)$ \\
& $29.16^{* * *}$ & $27.09 * * *$ & $23.92 * * *$ \\
Subjects & $(1.36)$ & $(1.34)$ & $(1.36)$ \\
Observations & 82 & 95 & 75 \\
$\mathrm{R}^{2}$ (overall) & 164 & 190 & 150 \\
$\mathrm{~F}$ & -0.001 & 0.058 & 0.096 \\
\hline
\end{tabular}

Robust standard errors in parentheses; errors clustered on groups; individual fixed effects. There are two observations per subject: one to summarize the subject's average contribution when facing a Stakeholder who had been generous to him, and one for his average contribution when facing a previously-ungenerous Stakeholder. The "nice dummy" is the indicator that differentiates these two observations for each subject. * significant at $10 \%$; ** significant at 5\%; *** significant at $1 \%$ 